\title{
Brief communication: Hurricane Dorian: automated near-real-time mapping of the "unprecedented" flooding in the Bahamas using synthetic aperture radar
}

\author{
Diego Cerrai ${ }^{1}$, Qing Yang $^{2}$, Xinyi Shen ${ }^{1}$, Marika Koukoula ${ }^{1}$, and Emmanouil N. Anagnostou ${ }^{1}$ \\ ${ }^{1}$ Department of Civil and Environmental Engineering, University of Connecticut, Storrs, CT 06279, USA \\ ${ }^{2}$ College of Civil Engineering and Architecture, Guangxi University, Nanning, Guangxi, 530004, China
}

Correspondence: Diego Cerrai (diego.cerrai@uconn.edu)

Received: 20 September 2019 - Discussion started: 29 October 2019

Revised: 16 April 2020 - Accepted: 21 April 2020 - Published: 27 May 2020

\begin{abstract}
In this communication, we present application of the automated near-real-time (NRT) system called RAdarProduced Inundation Diary (RAPID) to European Space Agency Sentinel-1 synthetic aperture radar (SAR) images to produce flooding maps for Hurricane Dorian in the northern Bahamas. RAPID maps, released $2 \mathrm{~d}$ after the event, show that coastal flooding in the Bahamas reached areas located more than $10 \mathrm{~km}$ inland, covering more than $3000 \mathrm{~km}^{2}$ of continental area. RAPID flood estimates from subsequent SAR images show the recession of the flood across the islands and present high agreement scores when compared to Copernicus Emergency Management Service (Copernicus EMS) estimates.
\end{abstract}

\section{Introduction}

Hurricane Dorian was the strongest Atlantic hurricane at landfall in terms of maximum sustained winds $(185 \mathrm{mph}$, $83 \mathrm{~m} \mathrm{~s}^{-1}$ ), tied with the 1935 Labor Day Hurricane (Landsea et al., 2014). Dorian's first record-breaking landfall occurred at 16:40 UTC and its second at 18:00 UTC on 1 September 2019, in the Abaco Islands in the northern Bahamas (NHC, 2019). A third landfall occurred at 03:00 UTC on 2 September at the eastern end of Grand Bahama and was characterized by maximum sustained winds of $80 \mathrm{~m} \mathrm{~s}^{-1}$ (180 mph). Tropical storm conditions battered the northern Bahamas for $72 \mathrm{~h}$, and locations in northeastern Grand Bahama suffered hurricane conditions for more than $40 \mathrm{~h}$. Between 08:00 UTC on 2 September and 14:00 UTC on 3 September, the National
Hurricane Center issued 30 consecutive hourly public advisories (NHC, 2019) indicating Hurricane Dorian was either moving at $0.5 \mathrm{~m} \mathrm{~s}^{-1}(1 \mathrm{mph})$ or was stationary, resulting in prolonged extreme conditions over the same areas. The prolonged damaging and record-breaking winds were just one aspect of this storm - one that was measured directly and in near-real time (NRT) by aircraft missions (HRD, 2019). In addition, the combined effect of storm surge and heavy precipitation brought about the extensive flooding that was the major cause of "unprecedented and extensive devastation", as described by Bahamian Prime Minister Hubert Minnis. Neither precipitation nor coastal surge could be directly measured because of the lack of a ground-based observational network.

In this and other remote areas around the world where ground-based measurements are not available, precipitation can be assessed using near-real-time (NRT) satellite estimates available through the National Aeronautics and Space Administration (NASA) Global Precipitation Measurement (GPM) Integrated Multi-satellitE Retrievals for GPM (IMERG), version 06 (Huffman et al., 2019). Without these automated estimates, gaining prompt situational awareness becomes difficult, which can cause delays in rescue operations.

Several space missions acquire synthetic aperture radar (SAR) data derived from low Earth observation (LEO) satellites that can be used for NRT systems: Sentinel-1, from the European Space Agency (ESA; Torres et al., 2012); TerraSAR-X, from the German Aerospace Center (DLR; Werninghaus and Buckreuss, 2009); COSMO-SkyMed, from 
the Italian Space Agency (ASI; Covello et al., 2010); RADARSAT-2, from the Canadian Space Agency (CSA; Morena et al., 2004); and ALOS-2/PALSAR-2, from the Japan Aerospace Exploration Agency (JAXA; Kankaku et al., 2013). Among these, only Sentinel-1 provides public access to SAR data that can be used to estimate flooding.

The nature of LEO satellites makes SAR data sparse, however, and, unlike with precipitation products, gaps cannot be filled using geosynchronous satellites. In fact, the spatial resolution needed for accurate flooding maps is 3 orders of magnitude higher than that required for a global precipitation product. Even when observations are present, no detailed processing methods exist for real-time retrieval of flooding data because underdetection or overdetection issues necessitate manual labor (Shen et al., 2019a).

Recently, we published the RAdar-Produced Inundation Diary (RAPID) NRT fully automated system (Shen et al., 2019a), which involves the processing of high-resolution $(10 \mathrm{~m})$ SAR images to allow the creation of rapid and efficient flood inundation maps by addressing both underdetection and overdetection. Differently than optical sensors, SAR images are nearly not affected by adverse weather conditions. As discussed in the Methodology section below, the system is triggered (Yang et al., 2019) by IMERG precipitation estimates (Huffman et al., 2019), and it processes Sentinel-1 SAR data.

In this brief communication, we present the early results we delivered with the RAPID NRT automated system $2 \mathrm{~d}$ after Hurricane Dorian hit the Bahamas, just a few hours after SAR data for the event became publicly available. We provide a short description of the methodology, and we detail the extent of flood inundation by analyzing RAPID maps.

\section{Methodology}

Only a few SAR-based flood delineation methods (e.g., Horritt et al., 2003; Martinis et al., 2009; Matgen et al., 2011; Giustarini et al., 2012; Lu et al., 2014; Chini et al., 2017; Cian et al., 2018) have the potential to be fully automated (Shen et al., 2019b). The RAPID algorithm (Shen et al., 2019a) is an automated system capable of producing NRT inundation maps by processing SAR observations. Because of the considerable computation, storage, and data transfer time that would be needed to run the RAPID algorithm blindly for every SAR image worldwide, we implemented a zoom-in triggering mechanism (Yang et al., 2019) that allows selection of areas of the world where flooding is possible. Areas are defined by the availability of SAR images associated with land that has received at least $60 \mathrm{~mm}$ of accumulated precipitation during the previous day or potentially fluvial flood areas indicated by hydrological station observations. Within the continental United States (CONUS) area, we use the National Oceanic and Atmospheric Administration (NOAA) Next-Generation Radar (NEXRAD) precipi- tation product (NOAA, 1991) and the U.S. Geological Survey (USGS) WaterWatch (https://waterwatch.usgs.gov/, last access: 18 September 2019). We use NASA's IMERG, version 06 (Huffman et al., 2019), for the rest of the world (Yang et al., 2019).

After being triggered, the RAPID core algorithm (Shen et al., 2019a) handles both polarizations of SAR images in ground-range-detected (GRD) mode through four steps: (1) identification of water and land pixels through a binary classification, (2) selection of water pixels connected to known water bodies and water areas not connected to known water bodies, (3) generation of a buffer region around the identified water bodies to reduce false negatives using less restrictive thresholds derived from the radar noise model, and (4) correction of the classification through a machinelearning algorithm that uses high-resolution topography (Farr et al., 2007), hydrography (Yamazaki et al., 2019), water occurrence (Pekel et al., 2016), and river bathymetry (Allen and Pavelsky, 2018; Chen et al., 2019; Yamazaki et al., 2014). In step (2), the noise-reduced persistent water extent (known water body) is computed using at least five overpasses acquired during non-flood conditions for each pixel.

The RAPID system has been quantitatively compared in past studies with manually derived flood maps using (overall, user, producer) agreement scores, representing (accuracy, true positive rate, precision) parameters of the confusion matrix. Specifically, for Hurricane Harvey, RAPID was compared with the Dartmouth Flood Observatory (DFO) comprehensive flood map of 30 August 2017 (Shen et al., 2019a) and with the USGS Dynamic Surface Water Extent (DSWE) northwestern flood map of 25 June 2019 (Yang et al., 2019). RAPID yielded consistently high agreement scores for Harvey $(93 \%, 75 \%, 77 \%)$ and the northwestern flood $(96 \%, 84 \%, 76 \%)$. For Hurricane Dorian, we are presenting a comparison between RAPID and the Copernicus Emergency Management Service (Copernicus EMS) firstestimate maps (available at https://emergency.copernicus.eu/ mapping/list-of-components/EMSR385/FEP/ALL, last access: 19 May 2020), both derived from the Sentinel-1 SAR observations. Copernicus EMS flooding maps are not available for the entire SAR images, but only for the Abaco Islands on 2 September 2019, and for Grand Bahama on 4 September 2019.

\section{Results}

Because of the extremely high amounts of precipitation related to Hurricane Dorian (up to more than $1400 \mathrm{~mm}$ over $3 \mathrm{~d}$; see Fig. 1), the RAPID system was automatically triggered for the northern Bahamas. Sentinel-1 SAR data were available at 23:44 UTC on 2 September and at 11:09 UTC on 4 September 2019.

At the time of the first overpass on 2 September, Dorian was located $20 \mathrm{~km}$ to the north of Grand Bahama (Fig. 1). 
Total Accumulated Precipitation between 00 UTC 01/09/2019 and 00 UTC 04/09/2019

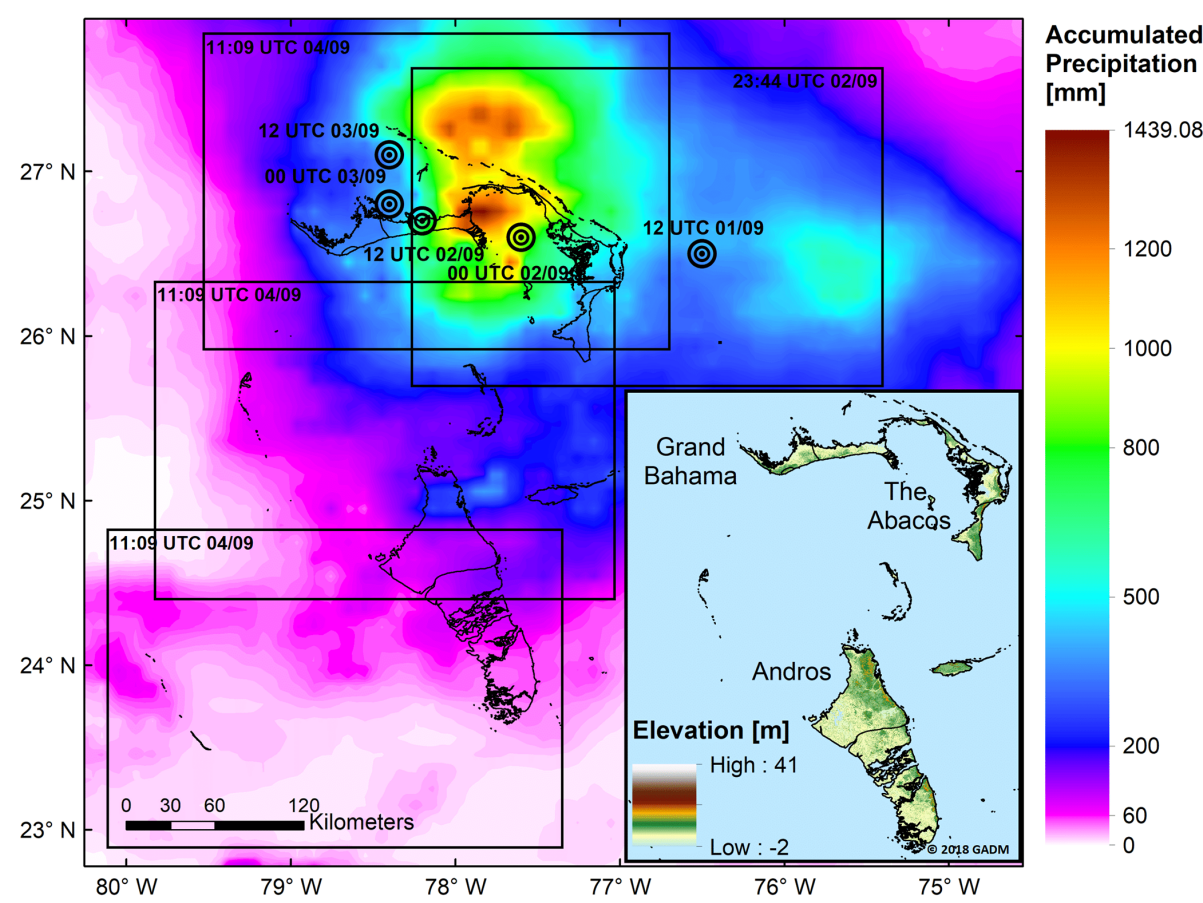

Figure 1. Background map: IMERG total accumulated precipitation between 00:00 UTC 1 September and 00:00 UTC 4 September 2019 (shaded), boundaries of Sentinel-1 SAR images (rectangles), and location (targets) of Hurricane Dorian from National Hurricane Center public advisories (NHC, 2019). Bottom right front map: elevation (Farr et al., 2007) of the study area. In both maps, Bahamas boundaries are delineated using the Global Administrative Areas dataset (Hijmans and University of California, 2015).

Sentinel-1 data covered the northeastern sector of Grand Bahama and all of Great Abaco, both located in the southeastern sector of the hurricane and therefore affected by southwesterly winds. Lower-elevation areas on the west coast of Great Abaco were suffering onshore tropical storm force winds, and flooding in these territories was extensive, covering $518 \mathrm{~km}^{2}$ of land, or $26 \%$ of the island (Fig. 2a).

On 2 September, offshore hurricane-force winds affected lower-elevation areas along the northern coast of Grand Bahama, which had been affected by onshore hurricane-force winds during the previous day. Despite the blowing of the winds away from the coast, proximity to the center of the hurricane did not allow the storm surge to retreat significantly. For this reason, these locations were also still experiencing extensive flooding: $138 \mathrm{~km}^{2}$ of the $308 \mathrm{~km}^{2}$ covered by the SAR images was flooded, amounting to $45 \%$ of eastern Grand Bahama (Fig. 2a). Since the first overpass occurred several hours after the passage of the hurricane, the flooded area shown in Fig. 2a represents a conservative estimate.

The second Sentinel-1 overpass entirely captured Great Abaco, Grand Bahama, Andros, New Providence, and other smaller islands of the archipelago on 4 September, when Dorian was located $300 \mathrm{~km}$ to the north of Grand Bahama. Despite the absence of storm surge at the time of the overpass, $17 \%$ of Great Abaco was still flooded, while flooding on
Grand Bahama had mostly receded (14\% of the island was still flooded).

On 3 September, high amounts of precipitation also fell on Andros Island, located approximately $200 \mathrm{~km}$ to the south of Dorian's path. The flooding map resulting from the automated trigger of the RAPID algorithm also showed extensive flooding on the low-lying terrain of this island, which received onshore winds during the entire duration of the event (Fig. 2b). On 4 September, the inundated area was $2193 \mathrm{~km}^{2}$ (37\% of the island), and flooding reached more than $10 \mathrm{~km}$ inland. RAPID flooding estimates of area and inland extent on the Andros Island are in agreement with the coarser-resolution product composited from the passive radiometers Visible Infrared Imaging Radiometer Suite (VIIRS) at $375 \mathrm{~m}$ pixel spacing and the Advanced Baseline Imager (ABI) at $1 \mathrm{~km}$, displayed on the International Charter "Space and Major Disasters" website at https://disasterscharter.org/image/journal/article.jpg?img_ $\mathrm{id}=3519568 \& \mathrm{t}=1568272371731$ (last access: 19 May 2020).

The agreement (overall, user, producer) scores between RAPID and Copernicus EMS flooding maps for the Abaco Islands on 2 and 4 September, derived from the confusion matrix shown in Table 1, were $(77 \%, 90 \%, 41 \%)$ and $(89 \%$, $61 \%, 86 \%)$, respectively. The high overall and user agreement scores for the 2 September flooding are also depicted in the flood maps of Fig. 2a, indicating a very good overlap of 
Flooding retreat and comparison between RAPID and Copernicus EMS

a)

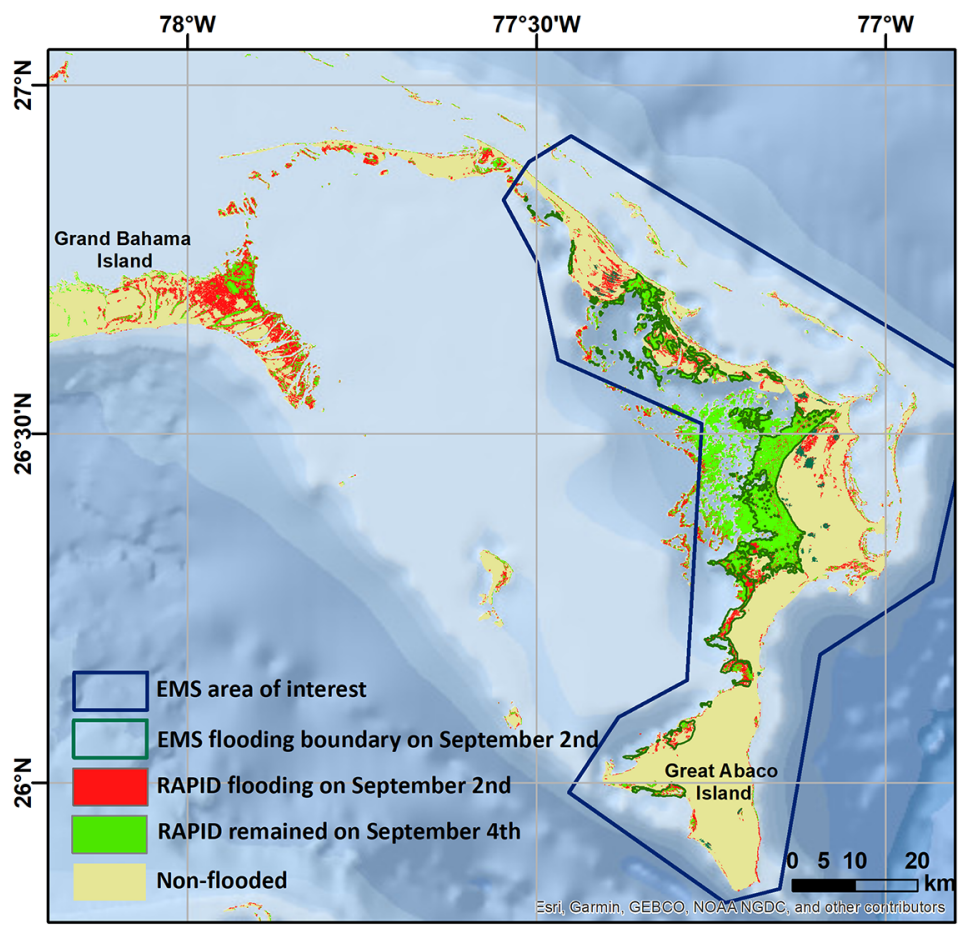

Flooding extent on September 4th

b)

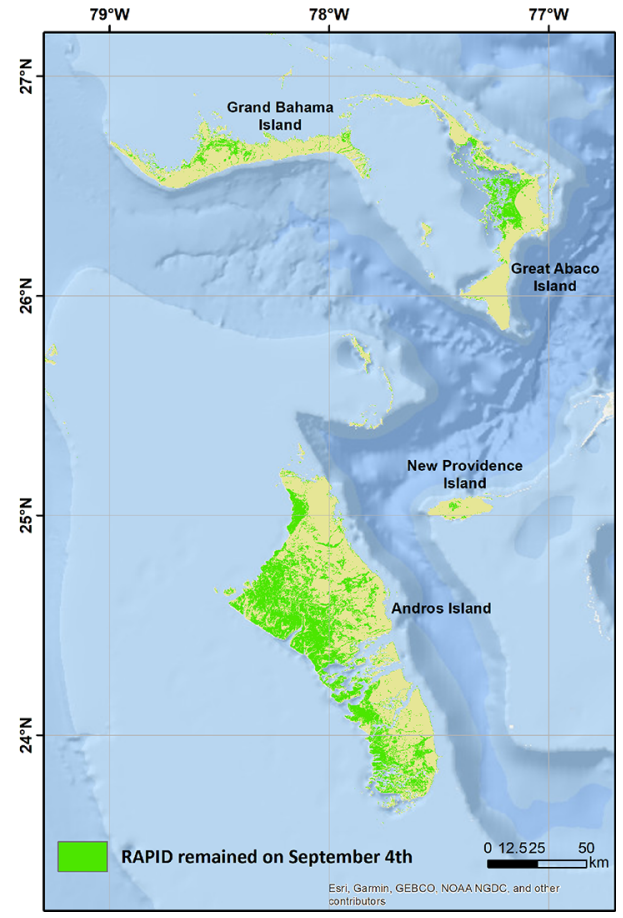

Figure 2. (a) Flooded and non-flooded areas on 2 and 4 September 2019 derived from the RAPID algorithm that processed SAR data from the Sentinel-1 overpasses, and flooded boundary on 2 September from Copernicus EMS. (b) RAPID flooding map for the entire northern and central Bahamas, for the 4 September 2019 Sentinel-1 overpass. For both images, ocean background is from World Ocean Base map (ESRI, 2014; list of contributors available at: http://downloads.esri.com/esri_content_doc/da/WorldOcean_ContributorsDA64.pdf, last access: 19 May 2020).

Table 1. Confusion matrix between RAPID and Copernicus EMS flooding products for the 2 September 2019 overpass over Great Abaco (left) and for the 4 September 2019 overpass over Grand Bahama (right). For each matrix, number and percentage of pixels are reported.

\begin{tabular}{llrr|rr}
\hline & & \multicolumn{2}{c}{ 2 September - Great Abaco } & \multicolumn{2}{c}{ 4 September - Grand Bahama } \\
\cline { 3 - 5 } Confusion matrix & \multicolumn{2}{c}{ Copernicus EMS } & \multicolumn{2}{c}{ Copernicus EMS } \\
\cline { 3 - 5 } & \multicolumn{2}{c}{ Flooded } & Non-flooded & Flooded & Non-flooded \\
\cline { 3 - 5 } & Flooded & $2274927(14.5 \%)$ & $3318143(21.1 \%)$ & $1880609(13.2 \%)$ & $32989(2.3 \%)$ \\
\multirow{2}{*}{ RAPID } & Non-flooded & $260335(1.7 \%)$ & $9847017(62.7 \%)$ & $1219786(8.6 \%)$ & $10710519(75.9 \%)$ \\
\hline
\end{tabular}

the two products over the coast of Great Abaco, while the relatively low producer agreement comes from the lack of flood detection by the Copernicus EMS algorithm over the multiple near-sea-surface-elevation islands, located in the front of the western coast of Great Abaco. The relatively low user agreement score between the two products on 4 September is due to the fact that RAPID classifies some non-flooded areas within the Copernicus EMS flooded boundary, which is expected to occur as a consequence of the flood recession.

According to the conservative flooding estimates shown in these maps, the total area covered by flooding in the Bahamas exceeded $3000 \mathrm{~km}^{2}$, spread over areas hundreds of kilometers away from each other. To assess the inundation extent over such vast and dispersed areas, recognition flights take days, and they cannot operate during such extreme weather conditions as were presented by the long-lasting hurricaneforce winds in the Bahamas. In contrast, a system such as RAPID can provide flooding estimates for any area of the world within hours of the data's becoming available. RAPID has the potential to be a fundamental tool for a fast and efficient emergency response.

\section{Closing remarks}

Hurricane Dorian heavily damaged the northern Bahamas with extreme winds and precipitation and extensive flooding. 
When large-scale weather-related devastation occurs in areas of the world that do not have in situ observation networks, an assessment of the situation based on hydrometeorological parameters is often difficult.

In this brief communication, we analyzed the flooding related to Hurricane Dorian in the Bahamas at $10 \mathrm{~m}$ pixel spacing through RAPID, which is an automated system producing near-real-time flood maps across the globe based on SAR images. Specifically, RAPID identifies possibly flooded areas using near-real-time high-resolution precipitation products and then processes SAR images to compute inundation maps.

For Hurricane Dorian, RAPID inundation maps showed that, several hours after the passage of the storm, $26 \%$ of Great Abaco, $45 \%$ of eastern Grand Bahama, and $37 \%$ of Andros were flooded, for a total area exceeding $3000 \mathrm{~km}^{2}$. We compared RAPID inundation maps with Copernicus EMS maps, both obtained from freely available, very highresolution ESA Sentinel-1 SAR observations, finding high agreement scores, and we discussed the differences between the two products for the case being examined. We believe the RAPID system's ability to map such a large area of inundation as soon as SAR observations were available makes it a fast fully automated method for consistently assessing flood extension and providing situational awareness.

The main limitation of the system is the occasional unavailability of timely satellite overpasses in conjunction with heavy precipitation events. For Hurricane Dorian, Sentinel1 images were not available at the peak of the event in the most affected area. This limitation can be overcome through international collaborations, such as the International Charter "Space and Major Disasters", Sentinel Asia, NASA-ISRO SAR Mission, and Copernicus Emergency Management Service - Mapping, that would increase the availability of data from other satellite missions.

Future extensions of this work will allow us to combine the rapidly derived inundated areas with high-resolution terrain elevation to identify flood levels and inversely estimate the surges that caused the flooding. Using this information, we would be able to extend the flood inundation estimates outside the SAR coverage, e.g., derive the 2 September flooding over the northwestern part of Grand Bahama, where Sentinel1 observations are not available. Furthermore, an estimate of the surge level can be valuable information for comparing with model forecasts for this event.

Data availability. Flood maps and data produced from RAPID during Hurricane Dorian are available at https: //s3.console.aws.amazon.com/s3/buckets/rapid-nrt-events/ Dorian-2019/?region=us-west $-2 \&$ tab=overview (Yang et al., 2020).
Author contributions. DC conceived and designed the study, supervised and administered the work, and wrote the original draft. QY and MK collected the data, performed the analysis, and designed and implemented computer programs. XS and ENA conceptualized the RAPID algorithm, co-administered the project, and reviewed and edited the manuscript.

Competing interests. The authors declare that they have no conflict of interest.

Acknowledgements. The authors of this publication had research support from Eversource Energy. The authors would like to thank the European Space Agency for granting free access to Sentinel-1 synthetic aperture radar data at $10 \mathrm{~m}$ grid spacing.

Review statement. This paper was edited by Kai Schröter and reviewed by Guy J.-P. Schumann and one anonymous referee.

\section{References}

Allen, G. H. and Pavelsky, T. M.: Global extent of rivers and streams, Science, 361, 585-588, 2018.

Chen, X., Shen, X., Li, H., Cui, Y., Liu, B., Fang, W., Yang, Q., and Hong, Y.: Construct Channel Network Topology From Remote Sensing Images by Morphology and Graph Analysis, IEEE Geosci. Remote S., https://doi.org/10.1109/LGRS.2019.2942107, accepted, 2019.

Chini, M., Hostache, R., Giustarini, L., and Matgen, P.: A hierarchical split-based approach for parametric thresholding of SAR images: Flood inundation as a test case, IEEE T. Geosci. Remote, 55, 6975-6988, 2017.

Cian, F., Marconcini, M., and Ceccato, P.: Normalized Difference Flood Index for rapid flood mapping: Taking advantage of EO big data, Remote Sens. Environ., 209, 712-730, 2018.

Covello, F., Battazza, F., Coletta, A., Lopinto, E., Fiorentino, C., Pietranera, L., Valentini, G., and Zoffoli, S.: COSMO-SkyMed an existing opportunity for observing the Earth, J. Geodyn., 49, 171-180, 2010.

ESRI: Ocean [basemap], World Ocean Base, available at: https://www.arcgis.com/home/item.html?id= 1e126e7520f9466c9ca28b8f28b5e500. (last access: 18 September 2019), 2014.

Farr, T. G., Rosen, P. A., Caro, E., Crippen, R., Duren, R., Hensley, S., Kobrick, M., Paller, M., Rodriguez, E., Roth, L., and Seal, D.: The shuttle radar topography mission, Rev. Geophys., 45, RG2004, https://doi.org/10.1029/2005RG000183, 2007.

Giustarini, L., Hostache, R., Matgen, P., Schumann, G. J. P., Bates, P. D., and Mason, D. C.: A change detection approach to flood mapping in urban areas using TerraSAR-X, IEEE T. Geosci. Remote, 51, 2417-2430, 2012.

Hijmans, R. and University of California, Berkeley, Museum of Vertebrate Zoology: Boundary, Bahamas, UC Berkeley, Museum of Vertebrate Zoology, available at: http://purl.stanford. edu/gr421mg4744 (last access: 18 September 2019), 2015. 
Horritt, M. S., Mason, D. C., Cobby, D. M., Davenport, I. J., and Bates, P. D.: Waterline mapping in flooded vegetation from airborne SAR imagery, Remote Sens. Environ., 85, 271-281, 2003.

HRD: Dorian 2019 missions, available at: https://www.aoml.noaa. gov/hrd/Storm_pages/dorian2019/mission.html, last access: 18 September 2019.

Huffman, G. J., Stocker, E. F., Bolvin, D. T., Nelkin, E. J., and Tan, J.: GPM IMERG Late Precipitation L3 1 day 0.1 degree x 0.1 degree V06, edited by: Savtchenko, A., Goddard Earth Sciences Data and Information Services Center (GES DISC), Greenbelt, MD, USA, https://doi.org/10.5067/GPM/IMERGDL/DAY/06, 2019.

Kankaku, Y., Suzuki, S., and Osawa, Y.: ALOS-2 mission and development status, in: 2013 IEEE International Geoscience and Remote Sensing Symposium - IGARSS, 21-26 July 2013, Melbourne, VIC, Australia, 2396-2399, IEEE, 2013.

Landsea, C. W., Hagen, A., Bredemeyer, W., Carrasco, C., Glenn, D. A., Santiago, A., Strahan-Sakoskie, D., and Dickinson, M.: A Reanalysis of the 1931-43 Atlantic Hurricane Databasem, J. Climate, 27, 6093-6118, 2014.

Lu, J., Giustarini, L., Xiong, B., Zhao, L., Jiang, Y., and Kuang, G.: Automated flood detection with improved robustness and efficiency using multi-temporal SAR data, Remote Sens. Lett., 5, 240-248, 2014.

Martinis, S., Twele, A., and Voigt, S.: Towards operational near real-time flood detection using a split-based automatic thresholding procedure on high resolution TerraSAR-X data, Nat. Hazards Earth Syst. Sci., 9, 303-314, https://doi.org/10.5194/nhess9-303-2009, 2009.

Matgen, P., Hostache, R., Schumann, G., Pfister, L., Hoffmann, L., and Savenije, H. H. G.: Towards an automated SAR-based flood monitoring system: Lessons learned from two case studies, Phys. Chem. Earth A/B/C, 36, 241-252, 2011.

Morena, L. C., James, K. V., and Beck, J.: An introduction to the RADARSAT-2 mission, Can. J. Remote Sens., 30, 221-234, 2004.

NHC: Hurricane Dorian Advisory Archive, available at: https: //www.nhc.noaa.gov/archive/2019/DORIAN.shtml?, last access: 18 September 2019.
NOAA: National Weather Service (NWS) Radar Operations Center: NOAA Next Generation Radar (NEXRAD) Level 2 Base Data. NOAA National Centers for Environmental Information, https://doi.org/10.7289/V5W9574V, 1991.

Pekel, J. F., Cottam, A., Gorelick, N., and Belward, A. S.: Highresolution mapping of global surface water and its long-term changes, Nature, 540, 418-422, 2016.

Shen, X., Anagnostou, E. N., Allen, G. H., Brakenridge, G. R., and Kettner, A. J.: Near-real-time non-obstructed flood inundation mapping using synthetic aperture radar, Remote Sens. Environ., 221, 302-315, 2019a.

Shen, X., Dacheng, W., Kebiao, M., Anagnostou, E. N., and Hong, Y.: Inundation Extent Mapping by Synthetic Aperture Radar: A Review, Remote Sens., 11, 879, https://doi.org/10.3390/rs11070879, 2019b.

Torres, R., Snoeij, P., Geudtner, D., Bibby, D., Davidson, M., Attema, E., Potin, P., Rommen, B., Floury, N., Brown, M., and Traver, I. N.: GMES Sentinel-1 mission, Remote Sens. Environ., 120, 9-24, 2012.

Werninghaus, R. and Buckreuss, S.: The TerraSAR-X mission and system design, IEEE T. Geosci. Remote, 48, 606-614, 2009.

Yamazaki, D., O’Loughlin, F., Trigg, M. A., Miller, Z. F., Pavelsky, T. M., and Bates, P. D.: Development of the global width database for large rivers, Water Resour. Res., 50, 3467-3480, 2014.

Yamazaki, D., Ikeshima, D., Sosa, J., Bates, P. D., Allen, G., and Pavelsky, T.: MERIT Hydro: A high-resolution global hydrography map based on latest topography datasets, Water Resour. Res., 55, 5053-5073, https://doi.org/10.1029/2019WR024873, 2019.

Yang, Q., Shen, X., Anagnostou, E. N., Eggleston, J. R., and Kettner, A. J.: An unprecedented High-Resolution Inundation Dataset delineated from SAR over the CONUS-from 2016 to Present, B. Am. Meteorol. Soc., accepted, 2019.

Yang, Q., Cerrai, D., Shen, Q., Koukoula, M., and Anagnostou, E. N.: Rapid NRT Events, available at: https://s3.console.aws.amazon.com/s3/buckets/rapid-nrt-events/ Dorian-2019/?region=us-west $2 \&$ tab=overview, last access: 22 May 2020. 